\title{
Erratum to: STUdy 3, 5 AND 12 OF INTERNATIONAL EDUCATION at Community Colleges
}

Rosalind Latiner Raby and Edward J. Valeau

\section{Erratum to:}

Study 3 in: Juanita Gamez Vargas, The Texas/Czech Republic International Connection: A Reciprocal Exchange of Faculty and Students, DOI 10.1057/978-1-137-53336-4_14

The affiliation of J.G. Vargas has been updated to "Jeanine Rainbolt College of Education, Department of Educational Leadership and Policy Studies, University of Oklahoma, Norman, OK, USA"

\section{Erratum to:}

Study 5 in: Paloma Rodriguez, Global Certificates: Bringing Intentionality and Ownership to Comprehensive Internationalization, DOI 10.1057/978-1-137-53336-4_16

The affiliation of P. Rodriguez has been updated to "International Education, Santa Fe College, Gainesville, FL, USA"

\section{Erratum to:}

Study 12 in: Marc Thomas, Community College Education Abroad and Business Internship Programs Cultivation of Competency in Communicating, Collaborating, and Critical Thinking, DOI 10.1057/978-1-137-53336-4_23

The chapter title was incorrect. The correct title is Community College International Internship Cultivation of Competence in Communication, Collaboration, and Critical Thinking 
The affiliation of Marc Thomas has been updated to "Consultant, New Orleans, LA, USA"

\section{Erratum to:}

Notes on Contributors, DOI 10.1057/978-1-137-53336-4

On Page 343, the first line of Kelly J. Kirkwood's biography has been changed from "She earned her doctoral degree in Doctoral Candidate in Adult, Community, and Higher Education" to "She earned her doctoral degree in Adult, Community, and Higher Education"

On Page 345, the degree of Juanita Gamez Vargas has been changed from Ed.D to Ph.D.

On Page 345, the biography for Marc Thomas has been updated to "Marc Thomas, Ed.D. served as faculty leaders abroad and global education coordinator for Lansing Community College in Michigan for 10 years and was selected twice as Visiting Scholar at the Japan Center for Michigan Universities in Shiga Prefecture. At this writing, he is traveling and teaching."

The updated online versions of the original chapters can be found at

DOI 10.1057/978-1-137-53336-4

DOI 10.1057/978-1-137-53336-4_14

DOI 10.1057/978-1-137-53336-4_16

DOI 10.1057/978-1-137-53336-4_23 